\title{
Effects of Diabetes Mellitus Induced by Alloxan on the Pharmacokinetics of Metformin in Rats: Restoration of Pharmacokinetic Parameters to the Control State by Insulin Treatment
}

\author{
Young Hee Choi ${ }^{1}$, Myung Gull Lee ${ }^{1}$, Inchul Lee ${ }^{2}$ \\ ${ }^{1}$ College of Pharmacy and Research Institute of Pharmaceutical Sciences, Seoul National University, Seoul, South Korea \\ ${ }^{2}$ Department of Diagnostic Pathology, College of Medicine, University of Ulsan, Asan Foundation, Asan Medical Center, \\ Seoul, South Korea
}

Received February 18, 2008; Revised March 18, 2008; Accepted March 19, 2008, Published March 21, 2008.

\begin{abstract}
PURPOSE. To test the effect of insulin treatment on the pharmacokinetics of metformin in rats with diabetes mellitus induced by alloxan (DMIA rats). The following results were reported from other studies. Metformin was metabolized via hepatic CYP2C11, 2D1, and 3A1/2 in rats. In DMIA rats, the protein expression and mRNA levels of hepatic CYP2C11 and 3A1/2 decreased and increased, respectively. In rat model of diabetes mellitus induced by streptozotocin, the protein expression of hepatic CYP2D1 was not changed. The increase in hepatic CYP1A2, 2B1, and $2 \mathrm{E} 1$, and decrease in hepatic CYP2C11 in DMIA rats was returned to the controls by insulin treatment. METHODS. Metformin (100 mg/kg) was administered intravenously and orally to the control rats, DMIA rats, and DMIA rats with insulin treatment for 3 weeks (DMIA rats with insulin).
\end{abstract} RESULTS. After intravenous administration of metformin to the DMIA rats, the $\mathrm{CL}_{\mathrm{R}}$ and $\mathrm{CL}_{\mathrm{NR}}$ of the drug were significantly slower than the controls. After oral administration of metformin to the DMIA rats, the AUC of the drug was also significantly greater than the controls. After intravenous administration of metformin to the DMIA rats with insulin, the significantly slower $\mathrm{CL}_{\mathrm{NR}}$ of the drug in the DMIA rats was returned to the controls. The altered pharmacokinetic indices observed following intravenous and oral administration of metformin to DMIA rats returned to the control values in the DMIA rats with insulin. CONCLUSIONS. The significantly slower $\mathrm{CL}_{\mathrm{NR}}$ of metformin in the DMIA rats could be due to the decrease in hepatic CYP2C11 than the controls. The comparable $\mathrm{CL}_{\mathrm{NR}}$ of metformin between the DMIA rats with insulin and the control rats could be due to restoration of hepatic CYP enzyme changes in DMIA rats to the controls.

\section{INTRODUCTION}

Metformin, a biguanide antihyperglycemic agent, is widely used in the management of type 2 diabetes mellitus. It lowers the blood glucose concentration without causing hypoglycemia (1). After intravenous (at doses of $0.25-1.0 \mathrm{~g}$ ) and oral (at doses of $0.5-1.5 \mathrm{~g}$ ) administration of metformin to four healthy volunteers, the terminal half-lives of the drug were $1.52-4.50 \mathrm{~h}, 78.9-99.9 \%$ of the dose were excreted in the urine via active renal tubular secretion, absorption of the drug was not complete (20-30\% of the oral dose were recovered from the feces) possibly due to an active, saturable absorption process, and the extent of absolute oral bioavailability $(F)$ of the drug was $33-55 \%$ (1). Metformin does not bind to human plasma proteins $(2,3)$. Metabolism of metformin was suggested in humans (1) based on its incomplete recovery in the urine after intravenous administration of the drug (2) and on a further study in which $20 \%$ of the dose was not accounted for (3). Recently, it was reported that metformin is mainly metabolized via hepatic microsomal cytochrome P450 (CYP) 2C11, 2D1, and $3 \mathrm{~A} 1 / 2$ (not via the CYP1A1/2, 2B1/2, and 2E1) in male Sprague-Dawley rats (4).

Corresponding Author: Myung G. Lee, College of Pharmacy and Research Institute of Pharmaceutical Sciences, Seoul National University, San 56-1, Shinlim-Dong, Kwanak-Gu, Seoul 151-742, South Korea, E-Mail: leemg@snu.ac.kr 
Kim et al. (5) reported that in male SpragueDawley rats with diabetes mellitus induced by alloxan (DMIA rats) and streptozotocin (DMIS rats), the protein expression and mRNA levels of hepatic CYP1A2, 2B1/2, 2E1, and 3A1/2 increased, whereas those of CYP2C11 decreased compared with the controls. The increase in hepatic CYP1A2 (6), 2B1 (6), and 2E1 $(7,8)$, and decrease in hepatic CYP2C11 $(6,9)$ were also reported in the DMIA rats. In addition to the changes in hepatic CYP isozymes, hepatotoxicity (10), impaired kidney function $(11,12)$, changes in the formation of glucuronide, glutathione, and sulfate conjugation (13) were also reported in the DMIA rats. Therefore, it could be expected that the pharmacokinetics of metformin could be changed in the DMIA rats. The changes in the pharmacokinetic parameters of drugs in the DMIA rats were reported, however, the changes with respect to changes in hepatic CYP isozymes were scarce except theophylline (5), torasemide (14), clarithromycin (15), oltipraz (16), chlorozoxazone (17), and diclofenac (18). The studies on metformin were not reported, since the CYP isozymes responsible for the metabolism of metformin in rats were reported recently (4).

Although metformin is widely used in the management of type 2 diabetes mellitus, the drug was also effective in type 1 diabetic patients of normal body weight with insulin therapy; metformin was effective in improving the insulin action in type 1 diabetic patients (19). Urakami et al. (20) reported that metformin may represent a useful adjuvant to the management of type 1 diabetes mellitus in adolescents and young adults who have poor glycemic control despite a large amount of insulin. In this regard, metformin was chosen in this study using DMIA rats, a type I diabetes mellitus model. The decrease in hepatic CYP2C11 and increase in hepatic CYP1A2, 2B1, and 3A1 in DMIA rats were returned to the controls by insulin treatment (6). Also it was reported that the body weight loss, weakness, and cachexy, with a significant increase in water intake, urine output, and blood glucose levels, and decrease in plasma insulin level in DMIA rats were close to the control levels after insulin treatment $(21,22)$. Hence, the effect of insulin on the pharmacokinetics of metformin after intravenous and oral administration to the DMIA rats was also investigated. The purpose of this study was to investigate the effects of type I diabetes mellitus induced by alloxan on the pharmacokinetics of metformin after intravenous and oral administration of the drug. We also evaluated whether insulin treatment affects the pharmacokinetics of metformin in the DMIA rats.

\section{METHODS AND MATERIALS}

\section{Chemicals}

Metformin hydrochloride and ipriflavone [internal standard for the high-performance liquid chromatographic (HPLC) analysis of metformin] were supplied from Dalim Medical (Seoul, South Korea) and Research Laboratory of Dong-A Pharmaceutical Company (Yongin, South Korea), respectively. Insulin was supplied from Green Cross Company (Yongin, South Korea). The reduced form of $\beta$-nicotinamide adenine dinucleotide phosphate (NADPH; as a tetrasodium salt), tri(hydroxymethyl)aminomethane (Tris $\left.{ }^{\circledR}\right)$ buffer, ethylenediamine tetraacetic acid (EDTA; as a disodium salt), and alloxan were purchased from Sigma-Aldrich Corporation (St. Louis, MO). Other chemicals were of reagent grade or HPLC grade.

\section{Animals}

Male Sprague-Dawley rats of 5-8 weeks of age (weighing 170-280 g) were purchased from Taconic Farms Inc. (Samtako Bio Korea, O-San, South Korea). The rats were randomly divided into two groups, control rats and the DMIA rats. The DMIA rats was further divided into two groups, the DMIA rats and the DMIA rats with insulin treatment for 3 weeks (DMIA rats with insulin). All rats were provided with food (Samyang Company, Pyeongteak, South Korea) and water ad libitum and maintained in a light-controlled room (light: 07001900, dark: 1900-0700) kept at a temperature of 22 $\pm 2{ }^{\circ} \mathrm{C}$ and a relative humidity of $55 \pm 5 \%$ (Animal Center for Pharmaceutical Research, College of Pharmacy, Seoul National University, Seoul, South Korea). Rats were housed in metabolic cages (Tecniplast, Varese, Italy) under the supply of filtered pathogen-free air. Protocols of this study were approved by Animal Care and Use Committee of College of Pharmacy of Seoul National University. 


\section{Induction of Diabetes Mellitus in Rats by Alloxan Injection}

Freshly prepared alloxan (dissolved in $0.9 \% \mathrm{NaCl}$ injectable solution to produce a concentration of 40 $\mathrm{mg} / \mathrm{mL}$ ) at a dose of $40 \mathrm{mg} / \mathrm{kg}$ was injected to overnight-fasted rats via the tail vein for two consecutive days to induce diabetes mellitus $(5,11,12,14-18)$. The same volume of $0.9 \% \mathrm{NaCl}-$ injectable solution was injected to the control rats. Just before the starting of experiment, the blood glucose level was measured using Medisense Optium Kit (Abbott Laboratories, Bedford, MA) and rats with blood glucose levels higher than 250 $\mathrm{mg} / \mathrm{dL}$ were chosen as a rat model of diabetes.

\section{Measurement of Liver and Kidney Function}

The following study was performed at the fourth day (just before the commencement of the experiment) in the control rats and the DMIA rats ( $n$ $=4$; each) to measure the liver and kidney functions. The 24-h urine sample was collected for the measurement of urine output and creatinine level. A blood sample was collected for the measurement of glucose level and hematocrit value (Readacroit Centrifuge; Clay Adams, Parsippany, NJ). A plasma sample was collected for the measurement of total proteins, albumin, urea nitrogen, glutamate oxaloacetate transaminase (GOT), glutamate pyruvate transaminase (GPT), and creatinine levels (analyzed by Green Cross Reference Lab., Seoul, South Korea). The whole kidney and liver of each rat were excised, rinsed with $0.9 \% \mathrm{NaCl}$-injectable solution, blotted dry with tissue paper, and weighed. Small portions of each organ were fixed in $10 \%$ neutral phosphate-buffered formalin and then processed for routine histological examination with hematoxylin-eosin staining. The initial and final body weights were also measured.

\section{Measurement of $V_{\max } K_{m}$ and $C L_{\text {int }}$ for the Disappearance of Metformin in Hepatic Microsomal Fractions of the Control and DMIA rats}

The procedures were similar to previously reported methods $(14,15)$. The whole livers of the control and DMIA rats ( $n=5$ and 4, respectively) were homogenized (Ultra-Turrax T25; Janke \& Kunkel,
IKA-Labortechnik, Staufeni, Germany) in approximately $20 \mathrm{~mL}$ of ice-cold buffer of $0.154 \mathrm{M}$ $\mathrm{KCl} / 50 \mathrm{mM}$ Tris- $\mathrm{HCl}$ in $1 \mathrm{mM}$ EDTA (pH 7.4). The homogenates were centrifuged $(10,000 \mathrm{~g}, 30$ $\mathrm{min}$ ) and the supernatant fraction was further centrifuged $(100,000 \mathrm{~g}, 90 \mathrm{~min})$. Microsomal protein content was measured using a reported method (23). The $V_{\max }$ (the maximum velocity) and the $K_{\mathrm{m}}$ (the Michaelis-Menten constant; the concentration at which the rate is one-half of the $\left.V_{\max }\right)$ for the disappearance of metformin were determined after incubating the above microsomal fractions (equivalent to $0.5 \mathrm{mg}$ protein), a $5 \mu \mathrm{L}$ aliquot of $0.9 \% \mathrm{NaCl}$-injectable solution that contained $1,2.5,5,7.5,20,50,100$, and $200 \mu \mathrm{M}$ of metformin base, and a $50 \mu \mathrm{L}$ aliquot of $0.1 \mathrm{M}$ phosphate buffer $(\mathrm{pH}$ 7.4) that contained $1 \mathrm{mM}$ NADPH in a final volume of $0.5 \mathrm{~mL}$ by adding 0.1 $\mathrm{M}$ phosphate buffer ( $\mathrm{pH}$ 7.4) in a water-bath shaker $\left[37^{\circ} \mathrm{C}, 500\right.$ oscillations per min (opm)]. All of the above microsomal incubation conditions were linear. The reaction was terminated by the addition of 1 $\mathrm{mL}$ of acetonitrile after $15 \mathrm{~min}$ incubation. The kinetic constants $\left(K_{\mathrm{m}}\right.$ and $\left.V_{\max }\right)$ for the disappearance of metformin were calculated using a non-linear regression method (24). The intrinsic clearance $\left(\mathrm{CL}_{\text {int }}\right)$ for the disappearance of metformin was calculated by dividing the $V_{\max }$ by the $K_{\mathrm{m}}$.

\section{Intravenous and Oral Studies in the Control and DMIA rats}

The procedures used for the pretreatment of rats including the cannulation of the jugular vein (for drug administration in the intravenous study) and the carotid artery (for blood sampling) were similar to a previously reported method (25). Early in the early morning at the fourth day after the start of the treatment with alloxan or $0.9 \% \mathrm{NaCl}$-injectable solution, metformin (metformin hydrochloride was dissolved in $0.9 \% \mathrm{NaCl}$-injectable solution) at a dose of $100 \mathrm{mg} / \mathrm{kg}$ as metformin base was infused (total infusion volume of approximately $0.6 \mathrm{~mL}$ ) over $1 \mathrm{~min}$ via the jugular vein of the control $(n=$ $9)$ and DMIA rats $(n=7)$. An approximately 0.12 $\mathrm{mL}$ aliquot of blood sample was collected via the carotid artery at 0 (to serve as a control), 1 (at the end of the infusion), 5, 15, 30, 60, 90, 120, 240, 360, 
480,600 , and $720 \mathrm{~min}$ after the start of the intravenous infusion of metformin. An approximately $0.3 \mathrm{~mL}$ aliquot of the heparinized $0.9 \% \mathrm{NaCl}$-injectable solution (20 units $/ \mathrm{mL}$ ) was used to flush each cannula immediately after each blood sampling to prevent blood clotting. Blood samples were centrifuged immediately and a $50 \mu \mathrm{L}$ aliquot of each plasma sample was stored at $-70{ }^{\circ} \mathrm{C}$ (Revco ULT 1490 D-N-S; Western Mednics, Asheville, NC) until used for the HPLC analysis of metformin (26). At the end of $24 \mathrm{~h}$, each metabolic cage was rinsed with $20 \mathrm{~mL}$ of distilled water and the rinsings were combined with 24-h urine sample. After measuring the exact volume of the 24-h urine and the combined urine samples, two $50 \mu \mathrm{L}$ aliquots of the combined urine sample were stored at $-70{ }^{\circ} \mathrm{C}$ until used for the HPLC analysis of metformin (26). At the same time $(24 \mathrm{~h})$, each rat was exsanguinated and sacrificed through cervical dislocation. And then, the abdomen was opened and the entire gastrointestinal tract (including its contents and feces) of each rat was removed, transferred into a beaker that contained $100 \mathrm{~mL}$ of methanol (to facilitate the extraction of metformin), and cut into small pieces using scissors. After manual shaking and stirring with a glass rod for 1 min, two $50 \mu \mathrm{L}$ aliquots of the supernatant were collected from each beaker and stored at $-70{ }^{\circ} \mathrm{C}$ until used for the HPLC analysis of metformin (26).

Metformin (the same solution used in the intravenous study) at a dose of $100 \mathrm{mg} / \mathrm{kg}$ was administrated orally (total oral volume of approximately $1.5 \mathrm{~mL})$ to the control $(n=7)$ and DMIA rats $(n=8)$ using a feeding tube. Blood samples were collected at $0,15,30,60,90,120$, $180,240,360,480,720,960,1200$, and $1440 \mathrm{~min}$ after oral administration of metformin. Other procedures were similar to those in the intravenous study.

\section{Intravenous and Oral Studies to the DMIA rats with or without Insulin Treatment for 3 Weeks}

The DMIA rats were divided into two groups, the DMIA rats on 25th day and the DMIA rats with insulin. For the DMIA rats with insulin, insulin was injected subcutaneously for 3 weeks at a dose of 30 units $/ \mathrm{kg} /$ day from 5 th day after tail vein injection of alloxan $(22,27)$. For the control and DMIA rats on
25 th day, the same volume of $0.9 \% \mathrm{NaCl}$-injectable solution was injected subcutaneously.

Metformin (the same solution that in the intravenous study) at a dose of $100 \mathrm{mg} / \mathrm{kg}$ as metformin base was infused (total infusion volume of approximately $0.6 \mathrm{~mL}$ ) over $1 \mathrm{~min}$ via the jugular vein of the control $(n=5)$, DMIA on 25th day $(n=$ $6)$, and DMIA rats with insulin $(n=7)$. Also metformin (the same solution used in the intravenous study) at a dose of $100 \mathrm{mg} / \mathrm{kg}$ as metformin base was administered orally (total infusion volume of approximately $1.5 \mathrm{~mL}$ ) to the control $(n=5)$, DMIA on 25th day $(n=8)$, and DMIA rats with insulin $(n=7)$ using a feeding tube. Other procedures were similar to those in the previous intravenous and oral studies.

\section{Measurement of Rat Plasma Protein Binding of Metformin Using the Equilibrium Dialysis Technique}

Plasma protein binding of metformin to the control and DMIA rats ( $n=5$ and 4, respectively) was measured using the equilibrium dialysis technique (28). One milliliter of plasma was dialyzed against $1 \mathrm{~mL}$ of isotonic Sørensen phosphate buffer $(\mathrm{pH}$ 7.4) that contained $3 \%(\mathrm{w} / \mathrm{v})$ dextran ('the buffer') in a $1 \mathrm{~mL}$ dialysis cell (Spectrum Medical Industries, Los Angeles, CA) using a Spectra/Por 4 membrane (mol. wt. cutoff of $12-14 \mathrm{KDa}$; Spectrum Medical Industries). After $24 \mathrm{~h}$ incubation, two $50 \mu \mathrm{L}$ aliquots were collected from each compartment and stored at $-70{ }^{\circ} \mathrm{C}$ until used for the HPLC analysis of metformin (26).

\section{HPLC Analysis of Metformin}

Concentrations of metformin in the samples were determined by a slight modification of a reported HPLC method (26); ipriflavone instead of hydrocodeine was used as an internal standard. In brief, a $50 \mu \mathrm{L}$ aliquot of biological sample was deproteinized with a $100 \mu \mathrm{L}$ aliquot of acetonitrile, and a $50 \mu \mathrm{L}$ aliquot of methanol that contained 10 $\mu \mathrm{g} / \mathrm{mL}$ of ipriflavone (internal standard) was added. After vortex-mixing and centrifugation $(16,000 \mathrm{~g}$, $10 \mathrm{~min}$ ), a $50 \mu \mathrm{L}$ aliquot of the supernatant was injected directly onto a reversed-phase $\left(\mathrm{C}_{18}\right)$ HPLC 
column. The mobile phase $(\mathrm{pH}=6), 10 \mathrm{mM}$ $\mathrm{KH}_{2} \mathrm{PO}_{4}$ : acetonitrile $=40: 60(\mathrm{v} / \mathrm{v})$, was run at a flow-rate of $1.5 \mathrm{~mL} / \mathrm{min}$, and the column eluent was monitored using an ultraviolet detector at $235 \mathrm{~nm}$.

\section{Pharmacokinetic Analysis}

The total area under the plasma concentration-time curve from time zero to time infinity (AUC) was calculated using the trapezoidal rule-extrapolation method; this method uses the logarithmic trapezoidal rule recommended by Chiou (29) for the calculation of the area during the phase of a declining level in plasma and the linear trapezoidal rule for the phase of a rising level in plasma. The area from the last datum point to time infinity was estimated by dividing the last measured concentration in plasma by the terminal-phase rate constant.

Standard methods (30) were used to calculate the following pharmacokinetic parameters using a non-compartmental analysis (WinNonlin 2.1; Pharsight Corp., Mountain View, CA); the timedaveraged total body, renal, and nonrenal clearances $\left(\mathrm{CL}, \mathrm{CL}_{\mathrm{R}}\right.$, and $\mathrm{CL}_{\mathrm{NR}}$, respectively), terminal halflife, the first moment of AUC (AUMC), the mean residence time (MRT), the apparent volume of distribution at steady state $\left(\mathrm{Vd}_{\mathrm{ss}}\right)$, and the $F(25)$. The peak plasma concentration $\left(C_{\max }\right)$ and the time to reach a $C_{\max }\left(T_{\max }\right)$ were directly read from the experimental data.

Glomerular filtration rate (GFR) was estimated by measuring the creatinine clearance $\left(\mathrm{CL}_{\mathrm{CR}}\right)$ assuming that kidney function was stable during the experimental period. The $\mathrm{CL}_{\mathrm{CR}}$ was measured by dividing the total amount of unchanged creatinine excreted in the 24-h urine by the $\mathrm{AUC}_{0-24 \mathrm{~h}}$ of creatinine in plasma.

The mean values of the $\mathrm{Vd}_{\mathrm{ss}}(31)$, the terminal halflife (32), and the each clearance (33) were calculated using the harmonic mean method.

\section{Statistical Analysis}

A $p<0.05$ was considered to be statistically significant using the $t$-test between the two means for the unpaired data or a Duncan's multiple range test of Statistical Package for the Social Sciences (SPSS) posteriori analysis of variance (ANOVA) among the three means for the unpaired data. All data are expressed as mean \pm standard deviation except median (ranges) for $T_{\max }$.

\section{RESULTS}

\section{Liver and Kidney Function}

Body weight, hematocrit, blood glucose level, 24-h urine output, plasma chemistry data, $\mathrm{CL}_{\mathrm{CR}}$, and relative liver and kidney weights in the control and DMIA rats are listed in Table 1. The plasma levels of total protein, albumin, GOT, and GPT, and relative liver weight in DMIA rats were comparable to the controls, however, they were in the reported ranges in the control rats (34). This suggests that the liver function did not seem to be impaired considerably in DMIA rats, and this could be supported based on the liver microscopy; there were no significant findings in the livers of both groups of rats.

The plasma level of urea nitrogen in the DMIA rats was significantly higher ( $101 \%$ increase) than the controls, however, the values in both groups of rats were in the reported ranges in the control rats (34). Moreover, the $\mathrm{CL}_{\mathrm{CR}}$ values were not significantly different between two groups of rats. This suggests that the kidney function also did not seem to be impaired considerably in the DMIA rats, and this could be supported based on the kidney microscopy; there were no significant findings in the kidneys of both groups of rats. Note that in the DMIA rats, the hematocrit, 24-urine output, and blood glucose level were significantly greater $(12.6,39.5$, and $184 \%$ increase, respectively), and final body weight (body weight gain) was significantly lighter $(24.9 \%$ decrease $)$ than the controls. However, the relative kidney weight in the DMIA rats was significantly heavier (30.3\% increase) than the controls.

\section{Measurement of $V_{\max } K_{m}$ and $C L_{i n t}$ for the Disappearance of Metformin in the Hepatic Microsomal Fractions}

The $V_{\max }, K_{\mathrm{m}}$, and $\mathrm{CL}_{\text {int }}$ for the disappearance of metformin in the hepatic microsomal fractions of the control and DMIA rats are listed in Table 2. In the DMIA rats, the $V_{\max }$ and the $K_{\mathrm{m}}$ were significantly faster (127\% increase) and higher (194\% increase), respectively, than the controls, 
suggesting that the maximum velocity for the disappearance (primarily metabolism) of metformin was faster than the controls and the affinity of the enzyme(s) for metformin decreased in the DMIA rats compared with the controls. In the DMIA rats, the $\mathrm{CL}_{\text {int }}$ for the disappearance of metformin was significantly slower $(22.4 \%$ decrease $)$ than the controls, suggesting that the metabolism of metformin decreased in the DMIA rats compared with the controls. In the DMIA rats, the total protein in the liver microsomes was significantly smaller than the controls $(47.5 \%$ decrease; $106 \pm 8.44$ and
$202 \pm 57.8 \mathrm{mg} /$ total liver weight).

\section{Pharmacokinetics of Metformin after Its Intravenous and Oral Administration to the Control and DMIA rats}

The data generated after $100 \mathrm{mg} / \mathrm{kg}$ intravenous doses of metformin to the control and DMIA rats are depicted in Figure 1 (A), and the relevant pharmacokinetic parameters are listed in Table 3.

Table 1. Mean ( \pm standard deviation) body weight, hematocrit, blood glucose level, 24-h urine output, plasma chemistry data, $\mathrm{CL}_{\mathrm{CR}}$, and relative liver and kidney weights in the control and DMIA rats.

Parameter Control $(n=4) \quad$ DMIA $(n=4)$

\begin{tabular}{lcccccc}
\hline Body weight $(\mathrm{g})$ & & & & & & \\
Initial & 185 & \pm & 10.0 & 203 & \pm & 15.5 \\
Final & 253 & \pm & 9.57 & 190 & \pm & $21.6^{\mathrm{a}}$ \\
Hematocrit (\%) & 45.3 & \pm & 1.34 & 51.0 & \pm & $3.67^{\mathrm{b}}$ \\
Blood glucose (mg/dL) & 128 & \pm & 6.78 & 363 & \pm & $78.0^{\mathrm{c}}$ \\
Urine output (mL/24-h) & 18.5 & \pm & 3.00 & 25.8 & \pm & $4.27^{\mathrm{b}}$ \\
Plasma & & & & & & \\
Total proteins (g/dL) & 5.63 & \pm & 0.171 & 5.60 & \pm & 0.535 \\
$\quad$ Albumin (g/dL) & 3.63 & \pm & 0.150 & 3.50 & \pm & 0.337 \\
$\quad$ Urea nitrogen (mg/dL) & 11.8 & \pm & 2.01 & 23.7 & \pm & $6.50^{\mathrm{b}}$ \\
$\quad$ GOT (IUd/L) & 73.3 & \pm & 7.09 & 79.8 & \pm & 12.3 \\
$\quad$ GPT (IU/L) & 25.3 & \pm & 2.75 & 31.5 & \pm & 5.67 \\
CL $\mathrm{CR}$ (mL/min/kg) & 4.11 & \pm & 0.395 & 5.03 & \pm & 0.829 \\
Liver weight (\% of body weight) & 2.94 & \pm & 0.0816 & 3.49 & \pm & 0.557 \\
Kidney weight (\% of body weight) & 0.775 & \pm & 0.0251 & 1.01 & \pm & $0.0866^{\mathrm{a}}$ \\
\hline
\end{tabular}

${ }^{a}$ Significantly different $(p<0.01)$ from control.

${ }^{\mathrm{b}}$ Significantly different $(p<0.05)$ from control.

${ }^{\mathrm{c}}$ Significantly different $(p<0.001)$ from control.

${ }^{\mathrm{d}}$ International unit. 
Table 2. Mean ( \pm standard deviation) $V_{\max }, K_{\mathrm{m}}$, and $\mathrm{CL}_{\text {int }}$ for the disappearance of metformin in hepatic microsomes of the control and DMIA rats.

\begin{tabular}{lccccccc} 
Parameter & Control $(\boldsymbol{n}=5)$ & \multicolumn{5}{c}{ DMIA $(\boldsymbol{n}=\mathbf{4})$} \\
\hline$V_{\max }(\mathrm{nmol} / \mathrm{min} / \mathrm{mg}$ protein $)$ & 1.57 & \pm & 0.334 & 3.57 & \pm & $1.03^{\mathrm{a}}$ \\
$K_{\mathrm{m}}(\mu \mathrm{M})$ & 53.0 & \pm & 16.0 & 156 & \pm & $61.9^{\mathrm{a}}$ \\
$\mathrm{CL}_{\text {int }}(\mathrm{mL} / \mathrm{min} / \mathrm{mg}$ protein $)$ & 0.0304 & \pm & 0.00359 & 0.0236 & \pm & $0.00238^{\mathrm{b}}$ \\
\hline
\end{tabular}

${ }^{a}$ Significantly different $(\mathrm{p}<0.01)$ from control; ${ }^{\mathrm{b}}$ Significantly different $(\mathrm{p}<0.05)$ from control.

After intravenous administration of metformin to DMIA rats, the changes in the pharmacokinetic parameters of the drug are as follows; the AUC was significantly greater $(33.3 \%$ increase), the $\mathrm{CL}, \mathrm{CL}_{\mathrm{R}}$, and $\mathrm{CL}_{\mathrm{NR}}$ were significantly slower (25.0, 18.1, and 35.8\% decrease, respectively), and the percentage of the intravenous dose of metformin excreted in the 24-h urine as an unchanged drug $\left(\mathrm{Ae}_{0-24 \mathrm{~h}}\right)$ was significantly greater $(8.15 \%$ increase) than the controls. Note that the contribution of $\mathrm{AUC}_{12} \mathrm{~h}-\infty$ to total AUC of metformin was less than $2.07 \%$ for all rats studied.

The data generated after $100 \mathrm{mg} / \mathrm{kg}$ oral doses of metformin to the control and DMIA rats are depicted in Figure 1 (B), and the relevant pharmacokinetic parameters are also listed in Table 3. After oral administration of metformin, absorption of the drug from the rat gastrointestinal tract was rapid; metformin was detected in plasma from the first or second blood sampling time (15 or $30 \mathrm{~min}$ ) for both groups of rats. After oral administration of metformin to the DMIA rats, the changes in the pharmacokinetic parameters of the drug are as follows; the AUC was significantly greater $(23.2 \%$ increase $)$, the terminal half-life was significantly longer $\left(22.6 \%\right.$ increase), the $C_{\max }$ was significantly higher (55.8\% increase), the $\mathrm{CL}_{R}$ was significantly slower (12.9\% decrease), and the $\mathrm{Ae}_{0-}$ $24 \mathrm{~h}$ was significantly greater $(7.18 \%$ increase $)$ than the control rats. Note that the contribution of $\mathrm{AUC}_{24}$ ${ }_{\mathrm{h}-\infty}$ to total AUC of metformin was less than $1.93 \%$ for all rats studied.

\section{Pharmacokinetics of Metformin after Its Intravenous and Oral Administration to the DMIA rats with Insulin}

The data generated after $100 \mathrm{mg} / \mathrm{kg}$ intravenous doses of metformin to the control, DMIA on 25th day, and DMIA rats with insulin are depicted in Figure 2 (A), and the relevant pharmacokinetic parameters are listed in Table 4 (A). After intravenous administration of metformin to the DMIA rats on 25th day, the changes in the pharmacokinetic parameters of the drug compared to the controls are as follows; the AUC was significantly greater $\left(62.4 \%\right.$ increase), the $C L, C_{R}$, and $\mathrm{CL}_{\mathrm{NR}}$ were significantly slower $(42.0,31.9$, and $62.2 \%$ decrease, respectively), and the $\mathrm{Ae}_{0-24 \mathrm{~h}}$ was significantly smaller (16.4\% increase) than those in the controls. Similar trends were also obtained from the DMIA rats (Table 3). Note that in the DMIA rats with insulin, the $\mathrm{AUC}, \mathrm{CL}_{\mathrm{R}}, \mathrm{CL}_{\mathrm{NR}}$, and $\mathrm{Ae}_{0-24 \mathrm{~h}}$ were returned to the controls (the values were significantly different compared with those in the DMIA rats on 25th day, but were not significantly different compared with the controls). Although the $C L$ values were significantly different among three groups of rats, the value in the DMIA rats with insulin was significantly slower and faster than that in the controls and DMIA rats on 25th day, respectively. This indicates that the $\mathrm{CL}$ of metformin in the DMIA rats with insulin was partially returned to the controls.

The data generated after $100 \mathrm{mg} / \mathrm{kg}$ oral doses of metformin to the control, DMIA on 25th 
day, and DMIA rats with insulin are depicted in Figure 2 (B), and the relevant pharmacokinetic parameters are also listed in Table 4 (B). After oral administration of metformin, absorption of the drug from the rat gastrointestinal tract was rapid; metformin was detected in plasma from the first or second blood sampling time (15 or $30 \mathrm{~min}$ ) for three groups of rats. After oral administration of metformin to the DMIA rats on 25th day, the changes in the pharmacokinetic parameters of the drug compared with the controls are as follows; the AUC was significantly greater $(45.1 \%$ increase), the $\mathrm{CL}_{\mathrm{R}}$ was significantly slower (16.7\% decrease), and the $\mathrm{Ae}_{0-24} \mathrm{~h}$ was significantly greater $(21.1 \%$ increase) than those in the controls. Similar trends were also obtained form the DMIA rats (Table 3). Note that in the DMIA rats with insulin, the AUC and the $\mathrm{Ae}_{0-24 \mathrm{~h}}$ were returned to the controls (the values were significantly different from those in the DMIA rats on 25th day, but were not significantly different from the controls). The $\mathrm{CL}_{\mathrm{R}}$ in the DMIA rats with insulin was slower than the controls, however, the value was comparable to the DMIA rats on 25th day. By insulin treatment in the DMIA rats on 25th day, the significantly smaller body weight gain, higher blood glucose level, and larger in 24-h urine output were returned to the controls.

\section{Plasma Protein Binding of Metformin Using the Equilibrium Dialysis Technique}

The plasma protein binding of metformin in the controls and the DMIA rats $(n=5$ and 4, respectively) were $12.7 \pm 5.57$ and $9.44 \pm 6.58 \%$, respectively; they were not significantly different. The adsorption of metformin to the equilibrium dialysis apparatus, which included the semipermeable membrane, was almost negligible; 85.3$106 \%$ of the spiked amounts of metformin were recovered from both the plasma and 'the buffer' compartments. The binding of metformin to $4 \%$ human serum albumin was independent of metformin concentrations ranging from 1 and 200 $\mu \mathrm{g} / \mathrm{mL}$; the mean value was $10.1 \%$ (28). Hence, a concentration of metformin of $10 \mu \mathrm{g} / \mathrm{mL}$ was arbitrarily chosen for the present plasma protein binding study.

\section{HPLC Analysis of Metformin}

The retention times of metformin and internal standard were approximately 4 and $6.5 \mathrm{~min}$, respectively. The quantitation limits of metformin in the rat plasma and urine samples were 0.05 and 1 $\mu \mathrm{g} / \mathrm{mL}$, respectively. The inter- and intra-day coefficients of variation were below 9.91 and $7.52 \%$ for the plasma and urine samples, respectively, in the concentration ranges of $0.05-$ $5,000 \mu \mathrm{g} / \mathrm{mL}$ and $1-1,000 \mu \mathrm{g} / \mathrm{mL}$ for the plasma and urine samples, respectively.

\section{DISCUSSION}

Induction of diabetes mellitus was evident in the DMIA rats based on significantly higher blood glucose level, significantly larger 24-h urine output, and significantly smaller body weight gain than the controls (Tables 1, 3, and 4). Significantly smaller body weight gain was related to the phosphorus depletion of soft tissues in alloxan-induced diabetes; phosphorus depletion appeared to body weight loss and negative phosphate balance (21).

The contribution of the $\mathrm{CL}_{R}$ to the $\mathrm{CL}$ of metformin was considerable in the controls and DMIA rats; the values were 59.7 and $65.2 \%$ for the control and DMIA rats, respectively (Table 3), indicating that metformin is mainly eliminated by the renal excretion $\left(\mathrm{CL}_{\mathrm{R}}\right)$ in rats. The contribution of the gastrointestinal (including the biliary) excretion of unchanged metformin to $\mathrm{CL}_{\mathrm{NR}}$ of the drug was almost negligible; the percentages of the intravenous dose of metformin recovered from the gastrointestinal tract at $24 \mathrm{~h}$ as an unchanged drug $\left(\mathrm{GI}_{24 \mathrm{~h}}\right)$ were 0.925 and $1.19 \%$ for the control and DMIA rats, respectively (Table 3). However, the smaller values of $\mathrm{GI}_{24} \mathrm{~h}, 0.925$ and $1.19 \%$, were not likely due to chemical and enzymatic degradation of metformin in rat's gastric fluid. It was reported (28) that metformin was stable up to $48 \mathrm{~h}$ incubation in various buffer solutions having $\mathrm{pHs}$ ranging from 1 to 12 and up to $24 \mathrm{~h}$ incubation in two rat gastric juices (pHs of 2.5 and 4.5, respectively). 
Table 3. Mean ( \pm standard deviation) pharmacokinetic parameters of metformin after intravenous and oral administration of the drug at a dose of $100 \mathrm{mg} / \mathrm{kg}$ to the control and DMIA rats.

\begin{tabular}{|c|c|c|c|c|c|c|c|c|c|c|c|c|c|}
\hline \multirow{3}{*}{$\begin{array}{l}\text { Parameter } \\
\text { Body weight (g) }\end{array}$} & \multicolumn{6}{|c|}{ intravenous } & \multirow{3}{*}{$\begin{array}{l}\text { Parameter } \\
\begin{array}{l}\text { Body weight } \\
\text { (g) }\end{array}\end{array}$} & \multicolumn{6}{|c|}{ Oral } \\
\hline & \multicolumn{3}{|c|}{$\begin{array}{c}\text { Control }(n= \\
9)\end{array}$} & \multicolumn{3}{|c|}{ DMIA $(n=7)$} & & \multicolumn{3}{|c|}{ Control $(n=7)$} & \multicolumn{3}{|c|}{ DMIA $(n=8)$} \\
\hline & & & & & & & & & & & & & \\
\hline Initial & 252 & \pm & 17.0 & 259 & \pm & 13.5 & Initial & 235 & \pm & 14.4 & 248 & \pm & 10.4 \\
\hline Final & 283 & \pm & 28.8 & 234 & \pm & $\underset{\mathrm{a}}{31.8}$ & Final & 261 & \pm & 16.0 & 233 & \pm & $10.0^{\mathrm{b}}$ \\
\hline $\begin{array}{l}\text { Blood glucose } \\
(\mathrm{mg} / \mathrm{dL})\end{array}$ & 118 & \pm & 11.5 & 377 & \pm & $110^{\mathrm{b}}$ & $\begin{array}{l}\text { Blood glucose } \\
(\mathrm{mg} / \mathrm{dL})\end{array}$ & 111 & \pm & 13.9 & 327 & \pm & $3.2^{\mathrm{b}}$ \\
\hline $\begin{array}{l}\text { Urine volume } \\
(\mathrm{mL} / 24-\mathrm{h})\end{array}$ & 12.0 & \pm & 6.08 & 22.1 & \pm & $\underset{\mathrm{a}}{6.67}$ & $\begin{array}{l}\text { Urine volume } \\
(\mathrm{mL} / 24-\mathrm{h})\end{array}$ & 5.60 & \pm & 2.88 & 13.4 & \pm & $4.27^{\mathrm{a}}$ \\
\hline $\begin{array}{l}\mathrm{AUC} \quad(\mu \mathrm{g} * \\
\mathrm{min} / \mathrm{mL})\end{array}$ & $\begin{array}{c}511 \\
0\end{array}$ & \pm & 726 & 6810 & \pm & $\underset{c}{1560}$ & $\begin{array}{l}\mathrm{AUC}(\mu \mathrm{g} * \\
\mathrm{min} / \mathrm{mL})\end{array}$ & 1940 & \pm & 247 & $\begin{array}{c}239 \\
0\end{array}$ & \pm & $286^{\mathrm{a}}$ \\
\hline $\begin{array}{l}\text { Terminal half- } \\
\text { life (min) }\end{array}$ & 162 & \pm & 36.1 & 161 & \pm & 48.1 & $\begin{array}{l}\text { Terminal half- } \\
\text { life (min) }\end{array}$ & 323 & \pm & 38.5 & 396 & \pm & $101^{\mathrm{c}}$ \\
\hline MRT (min) & 33.9 & \pm & 8.66 & 40.8 & \pm & 24.8 & $C_{\max }(\mu \mathrm{g} / \mathrm{mL})$ & 6.18 & \pm & 1.30 & 9.63 & \pm & $1.67^{\mathrm{b}}$ \\
\hline $\mathrm{CL}(\mathrm{mL} / \mathrm{min} / \mathrm{kg})$ & 19.6 & \pm & 3.02 & 14.7 & \pm & $\underset{c}{3.43}$ & $T_{\max }(\min )$ & 90 & 18 & & & & 120) \\
\hline $\begin{array}{l}\mathrm{CL}_{\mathrm{R}} \\
(\mathrm{mL} / \mathrm{min} / \mathrm{kg})\end{array}$ & 11.7 & \pm & 2.16 & 9.58 & \pm & $\underset{\mathrm{c}}{1.70}$ & $\begin{array}{l}\mathrm{CL}_{\mathrm{R}} \\
(\mathrm{mL} / \mathrm{min} / \mathrm{kg})\end{array}$ & 28.7 & \pm & 3.06 & 25.0 & \pm & $3.17^{\mathrm{c}}$ \\
\hline $\begin{array}{l}\mathrm{CL}_{\mathrm{NR}} \\
(\mathrm{mL} / \mathrm{min} / \mathrm{kg})\end{array}$ & 7.77 & \pm & 1.27 & 4.99 & \pm & $\frac{1.87}{\mathrm{a}}$ & $\begin{array}{l}\mathrm{Ae}_{0-24 \text { h }}(\% \text { of } \\
\text { dose })\end{array}$ & 55.7 & \pm & 2.82 & 59.7 & \pm & $2.22^{\mathrm{a}}$ \\
\hline $\mathrm{Vd}_{\mathrm{ss}}(\mathrm{mL} / \mathrm{kg})$ & 655 & \pm & 107 & 510 & + & 249 & $\begin{array}{l}\mathrm{GI}_{24} \text { h } \quad\left(\begin{array}{l}\% \\
\text { dose })\end{array}\right.\end{array}$ & 5.13 & \pm & 3.42 & 5.05 & \pm & 2.24 \\
\hline $\begin{array}{l}\mathrm{Ae}_{0-24} \text { h } \quad(\% \text { of } \\
\text { dose })\end{array}$ & 60.1 & \pm & 3.84 & 65.0 & $\perp$ & $\underset{\mathrm{c}}{4.44}$ & $F(\%)$ & & 3.0 & & & & \\
\hline $\begin{array}{l}\mathrm{GI}_{24} \text { h } \quad\left(\begin{array}{ll}\% & \text { of } \\
\text { dose }\end{array}\right)\end{array}$ & $\begin{array}{c}0.92 \\
5\end{array}$ & \pm & $\begin{array}{c}0.59 \\
8\end{array}$ & 1.19 & $I$ & $\begin{array}{c}0.56 \\
2\end{array}$ & & & & & & & \\
\hline
\end{tabular}

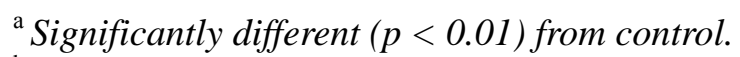

${ }^{\mathrm{b}}$ Significantly different $(p<0.001)$ from control.

${ }^{\mathrm{c}}$ Significantly different $(p<0.05)$ from control.

Moreover, it was also reported (4) that after intravenous administration of metformin at a dose of $100 \mathrm{mg} / \mathrm{kg}$ to six rats with bile duct cannulation, the biliary excretion of unchanged drug was almost negligible; the percentage of the intravenous dose of metformin excreted in the 24-h bile as unchanged drug was only $0.343 \%$. Hence, the $\mathrm{CL}_{\mathrm{NR}}$ of metformin listed in Table 3 could represent the metabolic clearance of the drug. Additionaly, the changes in the $\mathrm{CL}_{\mathrm{NR}}$ of metformin could represent the changes in the metabolism of the drug in rats.

The AUC values of metformin were doseproportional after both intravenous and oral administration of the drug at doses of 50,100, and 
$200 \mathrm{mg} / \mathrm{kg}$ to rats (28). Hence, the both intravenous and oral doses of $100 \mathrm{mg} / \mathrm{kg}$ were arbitrarily chosen for the present study.

After intravenous administration of metformin to the DMIA rats, the AUC of the drug was significantly greater than the controls due to significantly slower CL of metformin than the controls (Table 3 ). The significantly slower CL of metformin than the controls was due to significantly slower both the $\mathrm{CL}_{\mathrm{R}}$ and $\mathrm{CL}_{\mathrm{NR}}$ of the drug than the controls (Table 3 ). The significantly greater $\mathrm{Ae}_{0-24 \mathrm{~h}}$ in DMIA rats (Table 3) could be due to urine flow rate-dependent timed-interval renal clearance of metformin in rats; there was correlation (35) between 1/timed-interval renal clearance of metformin and 1/urine flow rate in both control rats and rats with diabetes mellitus induced by streptozotocin before and after insulin treatment; the more urine flow rate increased, the more metformin was excreted in the 24-h urine (Choi et al., 2008). The 24-h urine output in the DMIA rats was significantly larger than the controls (Tables 1 , 3 , and 4) as reported in other rat studies $(14-16,18)$.

After intravenous administration of metformin to the DMIA rats, the $\mathrm{CL}_{\mathrm{NR}}$ of the drug was also significantly slower than the controls (Table 3). This could be due to decrease in the expression and mRNA level of hepatic CYP2C11 in DMIA rats than the controls (5). As mentioned earlier, metformin was metabolized via hepatic CYP2C11, 2D1, and 3A1/2 in the control rats (4) and the expression and mRNA levels of hepatic CYP2C11 and 3A1 decreased and increased, respectively, in the DMIA rats compared with the controls (5). Although the study on DMIA rats was not reported, the expression of hepatic CYP2D1 was not changed in the DMIS rats (36). The above data suggested that the contribution of hepatic CYP3A1/2 to the metabolism of metformin in the DMIA rats did not seem to be considerable compared with that of hepatic CYP2C11. The hepatic first-pass effect of metformin was $27.1 \%$ based on the AUC difference between intravenous and intraportal administration of the drug to the control male Sprague-Dawley rats (28). Since metformin is a low hepatic extraction ratio drug in rats, its hepatic clearance depends more on the $\mathrm{CL}_{\text {int }}$ and free (unbound to plasma proteins) fractions of metformin in plasma rather than on the hepatic blood flow rate (37). The significantly slower $\mathrm{CL}_{\mathrm{NR}}$ of metformin in the DMIA rats (Table 3) could be supported by significantly slower $\mathrm{CL}_{\text {int }}$ than the controls (Table 2). The contribution of free fractions of metformin in plasma to the slower $\mathrm{CL}_{\mathrm{NR}}$ of metformin than the controls (Table 3) did not seem to be considerable; the plasma protein binding values of the drug were comparable between two groups of rats as mentioned earlier.

In the DMIA rats, the hematocrit was significantly greater than the controls (Table 1). The binding of metformin to blood cells was considerable; the mean value of equilibrium plasma-to-blood cells concentration ratio of metformin in rat blood at initial metformin blood concentrations of $1-10 \mu \mathrm{g} / \mathrm{mL}$ was $1.23-1.37$ (28). The bound fractions of adriamycin (38) and propranolol (39) to red blood cells were reported to act as barriers for their elimination. Hence, the significantly greater hematocrit in the DMIA rats (Table 1) could also contribute to the slower CL than the controls (Table 3).

After intravenous administration of metformin, the $\mathrm{CL}_{\mathrm{R}}$ of the drug was estimated as free fractions of metformin in plasma based on the $\mathrm{CL}_{\mathrm{R}}$ (Table 3) and plasma protein binding values of the drug. The values thus estimated were 13.4 and $10.6 \mathrm{~mL} / \mathrm{min} / \mathrm{kg}$ for the control and DMIA rats, respectively. The 13.4 and $10.6 \mathrm{~mL} / \mathrm{min} / \mathrm{kg}$ were considerably faster than the GFR (as estimated by $\mathrm{CL}_{\mathrm{CR}}$ ) for both groups of rats (Table 1), indicating that metformin is mainly secreted in the renal tubules for both groups of rats. Active renal tubular secretion of metformin in humans was also reported ( 1 and references therein). Based on the $C_{R}$ values of metformin based on plasma data (Table 3), reported renal blood flow rate of 54.8 (34) and 42.3 (40) $\mathrm{mL} / \mathrm{min} / \mathrm{kg}$ for the control and DMIA rats, respectively, and hematocrit and kidney weight (Table 1), the renal extraction ratios of metformin $\left(\mathrm{CL}_{\mathrm{R}}\right.$ of metformin / renal plasma flow rate; only for urinary excretion of unchanged drug) were estimated. The renal blood flow rates were estimated to be 707 and $418 \mathrm{~mL} / \mathrm{min} / 100 \mathrm{~g}$ kidney weight for the controls and 7-day alloxan (50 $\mathrm{mg} / \mathrm{kg}$ ) diabetic male CFE rats, respectively (40). The renal extraction ratios of metformin thus estimated were 39.0 and $46.2 \%$ for the control and DMIA rats, respectively, suggesting that the metformin is an intermediate renal extraction drug 
for both groups of rats.

After oral administration of metformin to the DMIA rats, the AUC of the drug was also significantly greater than the controls (Table 3) as shown after intravenous administration (Table 3). However, this was not likely due to increased absorption of metformin from the gastrointestinal tract than the controls. After oral administration of metformin, the $\mathrm{GI}_{24 \mathrm{~h}}$ values of the drug were 5.13 and $5.05 \%$ of the dose for the control and DMIA rats, respectively (Table 3 ). It is possible that this unchanged metformin, 5.13 and $5.05 \%$, might be partly attributed to the gastrointestinal (including biliary) excretion of the absorbed drug. Based on the linear pharmacokinetics (28), the mean "true" fractions of oral dose unabsorbed (" $F_{\text {unabs }}$ ") in this study could be estimated by the following equations (41);

$$
\begin{aligned}
& 0.0513=\text { " } F_{\text {unabs }} "+(0.380 \times 0.00925) \\
& \text { for control rats } \\
& 0.0505=\text { "F } F_{\text {unabs" }}+(0.351 \times \\
& \text { for DMIA rats }
\end{aligned}
$$

in which $0.380(0.351)$ and $0.00925(0.0119)$ are $F$ (Table 3) and $\mathrm{GI}_{24} \mathrm{~h}$ values of metformin after intravenous administration of the drug to the control rats (DMIA rats), respectively (Table 3).

Table 4. Mean ( \pm standard deviation) pharmacokinetic parameters of metformin after intravenous and oral administration of the drug at a dose of $100 \mathrm{mg} / \mathrm{kg}$ to the control, DMIA on 25th day, and DMIA rats with insulin.

\section{A. Intravenous}

\section{Parameter}

Body weight (g)

Initial

Final $^{\mathrm{a}}$

Blood glucose $(\mathrm{mg} / \mathrm{dL})^{\mathrm{a}}$

Urine volume $(\mathrm{mL} / 24-\mathrm{h})^{\mathrm{a}}$

$\operatorname{AUC}(\mu \mathrm{g} * \min / \mathrm{mL})^{\mathrm{a}}$

Terminal half-life (min)

MRT (min)

$\mathrm{CL}(\mathrm{mL} / \mathrm{min} / \mathrm{kg})^{\mathrm{b}}$

$\mathrm{CL}_{\mathrm{R}}(\mathrm{mL} / \mathrm{min} / \mathrm{kg})^{\mathrm{a}}$

$\mathrm{CL}_{\mathrm{NR}}(\mathrm{mL} / \mathrm{min} / \mathrm{kg})^{\mathrm{a}}$

$\mathrm{Vd}_{\mathrm{ss}}(\mathrm{mL} / \mathrm{kg})$

$\mathrm{Ae}_{0-24 \mathrm{~h}}(\% \text { of dose })^{\mathrm{a}}$

$\mathrm{GI}_{24 \mathrm{~h}}(\%$ of dose $)$

\section{Control}

$(n=5)$

$234 \pm 11.4$

$296 \pm 8.22$

$124 \pm 23.6$

$9.00 \pm 8.21$

$4260 \pm 332$

$183 \pm 8.17$

$36.5 \pm 8.21$

$24.3 \pm 2.09$

$16.0 \pm 2.08$

$7.86 \pm 1.51$

$721 \pm 69.5$

$66.4 \pm 6.73$

$0.951 \pm 1.04$
DMIA on 25th day $(n=6)$

$252 \pm \quad 21.4$

$273 \pm 22.3$

$371 \pm 45.9$

$22.8 \pm 8.80$

$6920 \pm 1160$

$190 \pm 44.2$

$32.0 \pm 7.61$

$14.1 \pm 3.14$

$10.9 \pm 1.95$

$2.97 \pm 1.53$

$573 \pm 147$

$77.3 \pm 5.87$

$2.67 \pm 3.51$
DMIA with insulin

$(n=7)$

\footnotetext{
${ }^{a}$ DMIA rats at 25th day was significantly different $(\mathrm{p}<0.05)$ from control rat and DMIA rats with insulin;

${ }^{\mathrm{b}}$ Each group of rats was significantly different $(\mathrm{p}<0.001)$.
} 
The " $F_{\text {unabs" }}$ " values thus estimated were 4.78 and $4.63 \%$ for the control and DMIA rats, respectively. Hence, an approximately $95 \%$ of the oral dose was absorbed from the gastrointestinal tract up to $24 \mathrm{~h}$ for both groups of rats. Although the study was not reported in DMIA rats, the testosterone 6- hydroxylase activity (a CYP3A1/2 marker in rats) in the small intestine in the DMIS rats reduced half that of the controls $(42)$. It was reported $(43,44)$ that CYP3A1 is mostly expressed in rat intestine, but CYP2D and 2C subfamilies are expressed very low in rat intestine. Moreover, the contribution of hepatic CYP3A1/2 to the metabolism of metformin in the DMIA rats did not seem to be considerable compared with that of hepatic CYP2C11 as mentioned earlier. Although the changes in intestinal CYP2C and 2D subfamilies in DMIA rats have not been reported yet, the effect of possible changes in intestinal CYP2C11, 2D1, and 3A1/2 in rat intestine on the pharmacokinetics of metformin in the DMIA rats did not seem to be considerable, if any. This could be supported by the following. The AUC differences between the control and the DMIA rats after both intravenous (33.3\% increase) and oral $(23.2 \%$ increase) administration were not considerable (Table 3), although the gastrointestinal first-pass effect of metformin was great, $53.8 \%$ of oral dose, in rats (28). Therefore, the greater AUC of metformin after oral administration of the drug to the DMIA rats could also be due to the same reasons as explained in the intravenous study.

\section{Table 4. Continued}

\section{B. Oral}

\begin{tabular}{|c|c|c|c|c|c|c|c|c|c|}
\hline \multirow{2}{*}{$\begin{array}{l}\text { Parameter } \\
\text { Body weight (g) }\end{array}$} & \multicolumn{3}{|c|}{ Control $(n=5)$} & \multicolumn{3}{|c|}{$\begin{array}{c}\text { DMIA on 25th day } \\
(n=8)\end{array}$} & \multicolumn{3}{|c|}{$\begin{array}{l}\text { DMIA with insulin } \\
\quad(n=7)\end{array}$} \\
\hline & & & & & & & & & \\
\hline Initial & 229 & \pm & 12.4 & 244 & \pm & 14.1 & 241 & \pm & 9.00 \\
\hline Final $^{\mathrm{a}}$ & 294 & \pm & 20.7 & 261 & \pm & 13.6 & 333 & \pm & 37.4 \\
\hline Blood glucose $(\mathrm{mg} / \mathrm{dL})^{\mathrm{b}}$ & 102 & \pm & 18.1 & 356 & \pm & 45.7 & 68.7 & \pm & 18.0 \\
\hline Urine volume $(\mathrm{mL} / 24-\mathrm{h})^{\mathrm{b}}$ & 15.0 & \pm & 3.87 & 21.5 & \pm & 3.67 & 15.5 & \pm & 3.39 \\
\hline $\operatorname{AUC}(\mu \mathrm{g} * \min / \mathrm{mL})^{\mathrm{b}}$ & 1530 & \pm & 197 & 2220 & \pm & 228 & 1760 & \pm & 307 \\
\hline Terminal half-life (min) & 342 & \pm & 119 & 411 & \pm & 131 & 335 & \pm & 195 \\
\hline$C_{\max }(\mu \mathrm{g} / \mathrm{mL})$ & 4.82 & \pm & 1.45 & 8.20 & \pm & 1.18 & 10.8 & \pm & 12.5 \\
\hline$T_{\max }(\min )$ & \multicolumn{3}{|c|}{$90(60-180)$} & \multicolumn{3}{|c|}{$60(30-180)$} & \multicolumn{3}{|c|}{$60(30-120)$} \\
\hline $\mathrm{CL}_{\mathrm{R}}^{\mathrm{c}}$ & 32.3 & \pm & 4.20 & 26.9 & \pm & 2.00 & 30.7 & \pm & 5.30 \\
\hline $\mathrm{Ae}_{0-24 \mathrm{~h}}(\% \text { of dose })^{\mathrm{b}}$ & 49.3 & \pm & 3.37 & 59.7 & \pm & 4.52 & 54.2 & \pm & 5.21 \\
\hline $\mathrm{GI}_{24 \mathrm{~h}}(\%$ of dose $)$ & 4.59 & \pm & 1.48 & 5.88 & \pm & 0.881 & 7.96 & \pm & 4.37 \\
\hline$F(\%)$ & 35.9 & & & 32.1 & & & 36.4 & & \\
\hline
\end{tabular}

\footnotetext{
${ }^{\mathrm{a}}$ Each group of rats was significantly different $(\mathrm{p}<0.001) ;{ }^{\mathrm{b}}$ DMIA rats at 25 th day was significantly different $(\mathrm{p}<$ $0.05)$ from control rat and DMIA rats with insulin; ${ }^{\mathrm{c}}$ DMIA rats at 25 th day was significantly different $(\mathrm{p}<0.05)$ from control rat, and comparable with DMIA rats with insulin.
} 


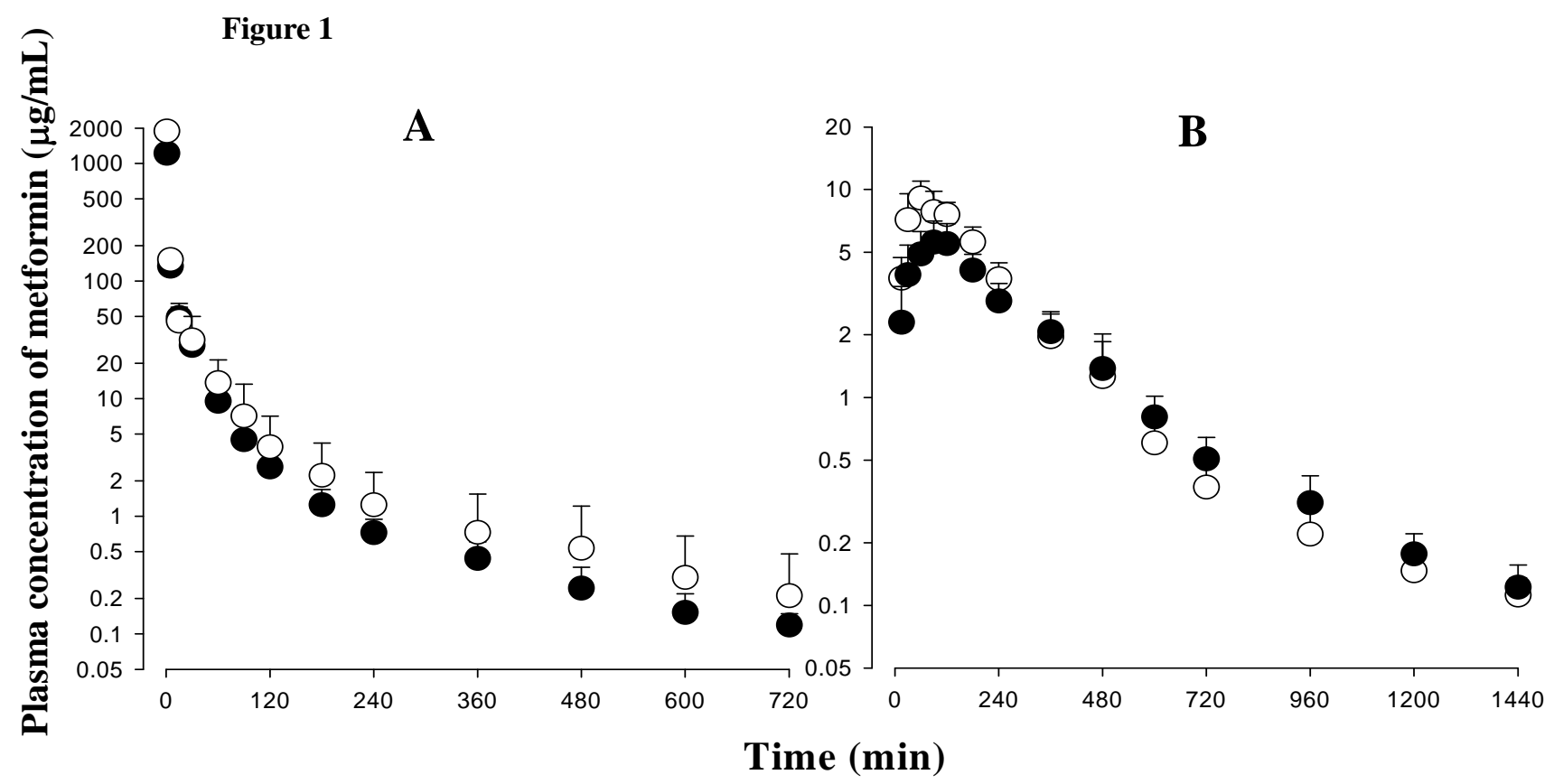

Figure 1: Mean arterial plasma concentration-time profiles of metformin after 1 min intravenous infusion of the drug at a dose of $100 \mathrm{mg} / \mathrm{kg}$ to the control $(n=9 ; \bullet)$ and DMIA rats $(n=7 ; \circ)$ (A) and after oral administration of the drug at a dose of $100 \mathrm{mg} / \mathrm{kg}$ to the control $(n=8 ; \bullet)$ and DMIA rats $(n=7 ; \circ)(B)$. Bars represent standard deviation.

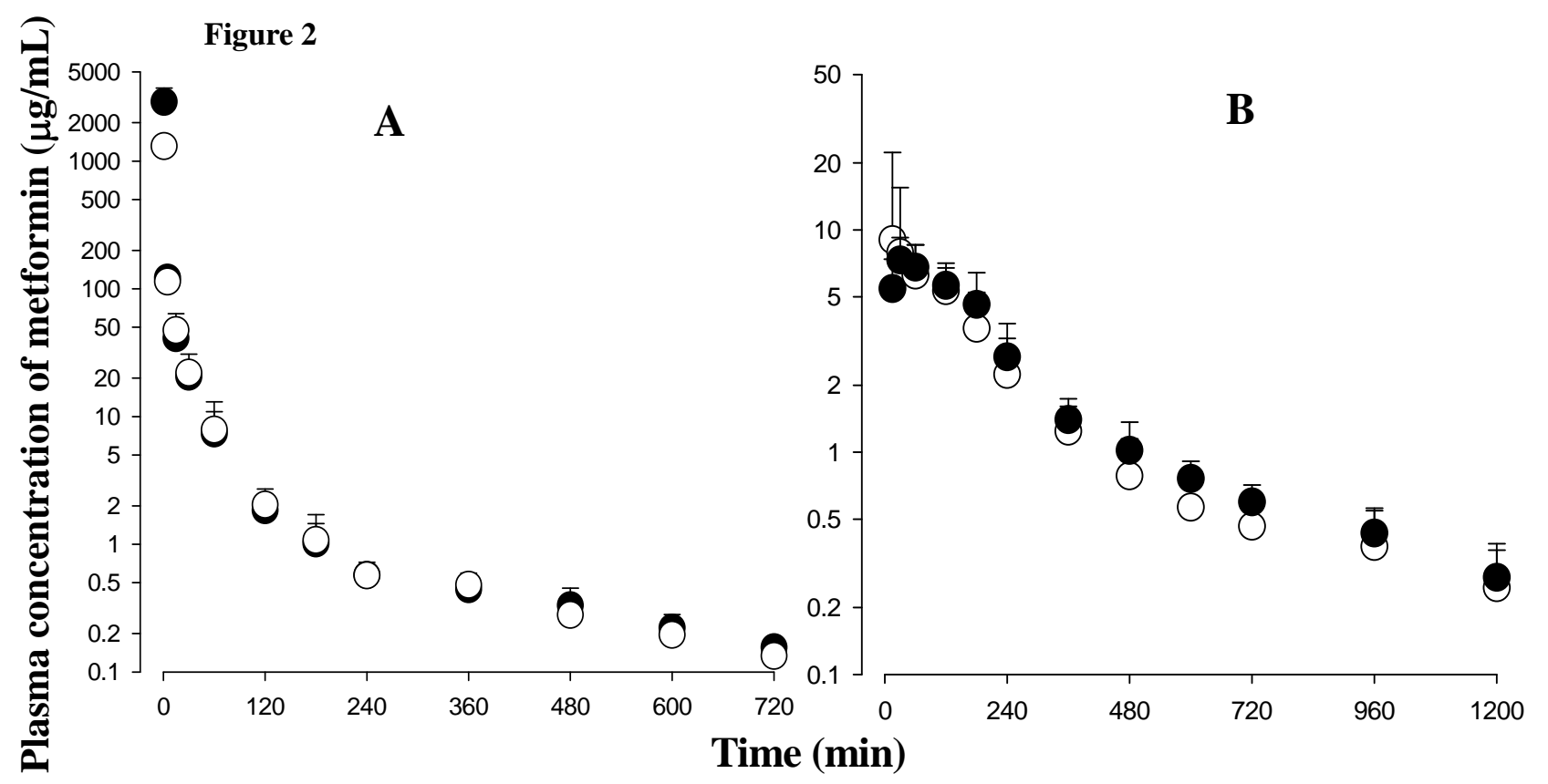

Figure 2: Mean arterial plasma concentration-time profiles of metformin after $1 \mathrm{~min}$ intravenous infusion of the drug at a dose of $100 \mathrm{mg} / \mathrm{kg}$ to the control $(n=5 ; \bullet)$, DMIA at 25th day $(n=6 ; \circ)$, and DMIA rats with insulin $(n=7 ; \triangle)$ (A) and after oral administration of the drug at a dose of $100 \mathrm{mg} / \mathrm{kg}$ to the control $(n=5 ; \bullet)$, DMIA at 25th day $(n=8 ; \circ)$, and DMIA rats with insulin $(n=7 ; \triangle)(B)$. Bars represent standard deviation. 
Note that the terminal half-lives of metformin after oral administration of the drug were considerably longer than those after intravenous administration (Table 3 ). This could be due to different blood sampling time schedules between two routes of administration. For comparison, the terminal half-lives after oral administration were estimated based on $720 \mathrm{~min}$ plasma data (the same time in the intravenous study); the values were close to those after intravenous administration $(164 \pm 60.4$ and $157 \pm$ $41.4 \mathrm{~min}$ for the control and DMIA rats, respectively).

Since metformin was also effective in type I diabetic patients with insulin therapy $(19,20)$, the effect of insulin on the pharmacokinetics of metformin in the DMIA rats was evaluated. After intravenous administration of metformin to the DMIA rats with insulin, the $C L_{N R}$ of the drug (the $\mathrm{CL}_{\mathrm{NR}}$ in the DMIA rats with insulin was significantly faster than that of the DMIA rats on 25th day) was returned to the controls (Table 4). Significantly faster $\mathrm{CL}_{\mathrm{NR}}$ of metformin in the DMIA rats with insulin (compared with that in the DMIA rats on 25th day) could be mainly due to restoration of hepatic CYP2C11 levels to the controls in the DMIA rats at 25th day by insulin treatment (6). The decrease in hepatic CYP2C11 and increase in hepatic CYP1A2, 2B1, 3A1 in the DMIA rats were returned to the controls by insulin treatment (6). In the DMIA rats with insulin, the significantly smaller $\mathrm{Ae}_{0-24 \mathrm{~h}}$ could be due to urine flow rate-dependent timed-interval renal clearance of metformin, since the 24-h urinary excretion was significantly smaller than that of without insulin. After intravenous and oral administration of metformin, some pharmacokinetic parameters changed in the DMIA rats on 25th day were returned to the control levels by insulin treatment for 3 weeks in the DMIA rats on 25th day. (Table 4).

\section{CONCLUSIONS}

After intravenous administration of metformin to the DMIA rats, the $\mathrm{CL}_{\mathrm{R}}$ and $\mathrm{CL}_{\mathrm{NR}}$ of the drug were significantly slower than the controls (Table 3 ). The significantly greater $\mathrm{Ae}_{0-24 \mathrm{~h}}$ in the DMIA rats could be due to urine flow rate-dependent timed-interval renal clearance of metformin. The significantly slower $\mathrm{CL}_{\mathrm{NR}}$ could be due to the decrease in the expression and mRNA level of hepatic CYP2C11 in the DMIA rats than the controls. After oral administration of metformin to the DMIA rats, the AUC of the drug was also significantly greater than the controls. However, this was not due to increase in absorption of metformin in the DMIA rats, and this could be due to the same reasons as explained in the intravenous study. After intravenous administration of metformin to the DMIA rats with insulin, the $\mathrm{CL}_{\mathrm{NR}}$ was significantly faster than that in the DMIA rats on 25th day and the value returned to the controls. This could be due to the restoration of hepatic CYP2C11 to the controls in the DMIA rats on 25th day by insulin treatment. After intravenous and oral administration of metformin to the DMIA rats on 25th day, some pharmacokinetic parameters of the drug were returned to the controls by insulin treatment.

\section{ACKNOWLEDGMENTS}

This work was supported in part by a grant from the 2007 BK21 Project for Applied Pharmaceutical Life Sciences.

\section{Nonstandard abbreviations:}

HPLC, high-performance liquid chromatography; AUC, total area under the plasma concentrationtime curve from time zero to time infinity; CL, time-averaged total body clearance; $\mathrm{CL}_{\mathrm{R}}$, timeaveraged renal clearance; $\mathrm{CL}_{\mathrm{NR}}$, time-averaged nonrenal clearance; $\mathrm{CL}_{\mathrm{CR}}$, time-averaged creatinine clearance; $\mathrm{Vd}_{\mathrm{ss}}$, apparent volume of distribution at steady state; MRT, mean residence time; $V_{\max }$, maximum velocity; $K_{\mathrm{m}}$, apparent Michaelis-Menten constant; $\mathrm{CL}_{\text {int }}$, intrinsic clearance; $C_{\max }$, peak plasma concentration; $T_{\max }$, time to reach a $C_{\max }$; $\mathrm{Ae}_{0-24 \mathrm{~h}}$, percentage of the dose excreted in the 24-h urine; $\mathrm{GI}_{24} \mathrm{~h}$, percentage of the dose recovered from the gastrointestinal tract (including its contents and feces) at $24 \mathrm{~h} ; \quad F$, extent of absolute oral bioavailability.

\section{REFERENCES}

[1] Scheen, A.J., Clinical pharmacokinetics of metformin. Clin Pharmacokinet, 30:359-371, 1996.

[2] Sirtori, C.R., Franceschini, G., Galli-Kienle, M., 
Cighetti, G., Galli, G., Bondioli, A., Conti, F., Disposition of metformin (N,Ndimethylbiguanide) in man. Clin Pharmacol Ther, 24:683-693, 1978.

[3] Tucker, G.T., Casey, C., Phillips, P.J., Connor, H., Ward, J.D., Woods, H.F., Metformin kinetics in healthy subjects and in patients with diabetes mellitus. Br J Clin Pharmacol, 12:235-246, 1981.

[4] Choi, Y.H., and Lee, M.G., Effects of enzyme inducers and inhibitors on the pharmacokinetics of metformin in rats: involvement of CYP2C11, 2D1, and $3 \mathrm{~A} 1 / 2$ for the metabolism of metformin. Br J Pharmacol, 149:424-430, 2006.

[5] Kim, Y.C., Lee, A.K., Lee, J.H., Lee, I., Lee, D.C., Kim, S.H., Kim, S.G., Lee, M.G., Pharmacokinetics of theophylline in diabetes mellitus rats: induction of CYP1A2 and CYP2E1 on 1,3-dimethyluric acid formation. Eur J Pharm Sci, 26:114-123, 2005.

[6] Yamazoe, Y., Murayama, N., Shimada, M., Yamauchi, K., Kato, R., Cytochrome P450 in livers of diabetic rats: regulation by growth hormone and insulin. Arch Biochem Biophys, 268:567-575, 1989.

[7] Dong, Z., Hong, J., Ma, Q., Li, D., Bullock. J., Gonzalez, F.J., Park, S.S., Gelboin, H.V., Yang C.S., Mechanism of induction of cytochrome P$450_{\mathrm{ac}} \quad\left(\mathrm{P}-450_{\mathrm{j}}\right)$ in chemically induced and spontaneously diabetic rats. Arch Biochem Biophys, 263:29-35, 1988.

[8] Li, L., Zhang, Y., Changes of CYP2E1 activity in diabetic rat model. Yao Xue Xue Bao (Acta Pharmaceutica Sinica), 33:891-895, 1998.

[9] Vega, P., Gaule, C., Mancila, J., Del Villar, E., Comparison of alloxan and streptozotocin induced diabetes in rats: differential effects on microsomal drug metabolism. Gen Pharmacol, 24:489-495, 1993.

[10] Price, V.F., Jollow, D.J., Strain differences in susceptibility of normal and diabetic_rats to acetaminophen hepatotoxicity. Biochem Pharmacol, 35:687-695, 1986.

[11] Park, J.H., Lee, W.I., Yoon, W.H., Park, Y.-D., Lee, J.-S., Lee, M.G., Pharmacokinetic and pharmacodynamic changes of furosemide after intravenous and oral administration to rats with alloxan-induced diabetes mellitus. Biopharm Drug Dispos, 19:357-364, 1998.

[12] Kim, S.H., Kim, W.B., Lee, M.G., 1998. Pharmacokinetics of a new carbapenem, DA-1131, after intravenous administration to rats with alloxan-induced diabetes mellitus. Biopharm Drug Dispos, 19:303-308, 1998.

[13] Watkins, J.B. III, Sherman, R.A., Diabetes mellitus-induced alternations of hepatobiliary function. Pharmacol Rev, 47:1-23, 1995.

[14] Kim, Y.C., Oh, E.Y., Kim, S.H., Lee, M.G., Pharmacokinetics and pharmacodynamics of intravenous torasemide in diabetic rats induced by alloxan or streptozotocin. Biopharm Drug Dispos, 26:371-378, 2005.

[15] Kim, Y.C., Lee, J.H., Kim, S.H., Lee, M.G., Effect of CYP3A1 induction on clarithromycin pharmacokinetics in rats with diabetes mellitus. Antimicrob Agents Chemother, 49:2528-2532, 2005.

[16] Bae, S.K., Kim, J.Y., Yang, S.H., Kim, J.W., Kim, T., Lee, M.G., Pharmacokinetics of oltipraz in rat models of diabetes mellitus induced by alloxan or streptozotocin. Life Sci, 78:2287-2294, 2006.

[17] Baek, H.W., Bae S.K., Lee, M.G., Sohn, Y.T., Pharmacokinetics of chlorozoxazone in rats with diabetes: Induction of CYP2E1 on 6hydroxychlorozoxazone formation. J Pharm Sci, 95:2452-2462, 2006.

[18] Kim, Y.C., Oh, E.Y., Kim, S.H., Lee, M.G., Pharmacokinetics of diclofenac in rat model of diabetes mellitus induced by alloxan or streptozotocin. Biopharm Drug Dispos, 27:85-92, 2006.

[19] Gin, H., Messerchmitt, C., Brottier, E., Aubertin, J., Metformin improved insulin resistance in type I, insulin-dependent, diabetic patients. Metabolism, 34:923-925, 1985.

[20] Urakami, T., Morimoto, S., Owada, M., Harada, $\mathrm{K}$., Usefulness of the addition of metformin to insulin in pediatric patients with type 1 diabetes mellitus. Pediatr Intravenous, 47:430-433, 2005.

[21] Locatto, M.E., Di Loreto, V., Fernandez, M.C., Caferra, D., Puche, R.C., Relative weight of glucose, insulin, and parathyroid hormone in urinary loss of phosphate by chronically diabetic rats. Acta Diabetol, 34:211-216, 1997.

[22] Spadella, C.T., Lerco, M.M., Machado, J.L.M., Macedo, C.S., Long-term effects of insulin therapy, islet transplantation, and pancreas transplantation in the prevention of glomerular changes in kidneys of alloxan-induced diabetic rats. Transplant Proc, 37:3468-3471.

[23] Bradford, M.M., A rapid and sensitive method for the quantitation of microgram quantities of protein utilizing the principle of protein-dye binding. Anal Biochem, 72:248-254, 1976.

[24] Duggleby, R.G., Analysis of enzyme progress curves by nonlinear regression. Methods Enzymol, 249:61-90, 1995.

[25] Kim, S.H., Choi, Y.M., Lee, M.G., Pharmacokinetics and pharmacodynamics of furosemide in protein-calorie malnutrition. $J$ Pharmacokinet Biopharm, 21:1-17, 1993. 
[26] Hale, T.W., Kristensen, J.H., Hackett, L.P., Kohan, R., Ilett, K.F., Transfer of metformin into human milk. Diabetologia, 45:1509-1514, 2002.

[27] Bae, S.K., Yang, S.H., Lee, S.J., Kwon, J.W., Kim, W.B., Lee, D.C., Lee, M.G., Pharmacokinetic changes of DA-7867, a new oxazolidinone, after intravenous and oral administration to rats with short-term and long-term diabetes mellitus induced by streptozotocin. Eur J Pharm Sci, 25: 337-345, 2005.

[28] Choi, Y.H., Kim, S.G., Lee, M.G., Doseindependent pharmacokinetics of metformin after intravenous and oral administration in rats: hepatic and gastrointestinal first-pass effects. $J$ Pharm Sci, 95:2543-2552, 2006.

[29] Chiou, W.L., Critical evaluation of potential error in pharmacokinetic studies using the linear trapezoidal rule method for the calculation of the area under the plasma level-time curve. $J$ Pharmacokinet Biopharm, 6:539-546, 1978.

[30] Gibaldi, M., and Perrier, D., Pharmacokinetics. 2nd ed. Marcel-Dekker, New York, NY, USA, 1982.

[31] Chiou, W.L., New calculation method for mean apparent drug volume of distribution and application to rational dosage regimens. J Pharm Sci, 68:1067-1069, 1979.

[32] Eatman, F.B., Colburn, W.A., Boxenbaum, H.G., Posmanter, H.N., Weinfeld, R.E., Ronfeld, R., Weissman, L., Moore, J.D., Gibaldi, M., Kaplan, S.A., Pharmacokinetics of diazepam following multiple dose oral administration to healthy human subjects. J Pharmacokinet Biopharm, 5:481-494, 1979.

[33] Chiou, W.L., New calculation method of mean total body clearance of drugs and its application to dosage regimens. J Pharm Sci, 69:90-91, 1980.

[34] Mitruka, B.M., and Rawnsley, H.M., Clinical, biochemical and hematological reference values in normal experimental animals and normal humans, 2nd ed. Masson Publishing, New York, NY, USA, 1981.
[35] Chiou, W.L., A new simple approach to study the effect of changes in urine flow and/or urine $\mathrm{pH}$ on renal clearance and its applications. Int $\mathrm{J}$ Cin Pharmacol Ther Toxicol, 24:519-527, 1986.

[36] Sakuma, T., Honma, R., Maguchi, S., Tamaki, H., Nemoto, N., Different expression of hepatic and renal cytochrome P450s between the streptozotocin-induced diabetic mouse and rats. Xenobiotica, 31:223-237, 2001.

[37] Wilkinson, G.R., and Shand, D.G., A physiological approach to hepatic drug clearance. Clin Pharmacol Ther, 18:377-390, 1975.

[38] Lee, H.J., and Chiou, W.L., Erythrocytes as barriers for drug elimination in the isolated rat liver. I. Doxorubicin. Pharm Res, 6:833-839, 1989.

[39] Lee, H.J., and Chiou, W.L., Erythrocytes as barriers for drug elimination in the isolated rat liver. II. Propranolol. Pharm Res, 6:840-843, 1989.

[40] Foy, J.M., and Salih, A.K.M., Glomerular filtration rate and kidney blood flow in alloxan and streptozotocin diabetic rats. Experientia, 5:1084-1086, 1979.

[41] Lee, M.G., and Chiou, W.L., Evaluation of potential causes for the incomplete bioavailability of furosemide: Gastric first-pass metabolism. $J$ Pharmacokinet Biopharm, 11:623-640, 1983.

[42] Raza, H., Ahmed, I., Lakhani, M.S., Sharma, A.K., Pallot, D., Montague, W., Effect of bitter melon (Momordica charantia) fruit juice on the hepatic cytochrome P450-dependent monooxygenases and glutathione S-transferases in streptozotocininduced diabetic rats. Biochem Pharmacol, 52:1639-1642, 1996.

[43] Kaminsky, L.S., Zhang, Q.-Y., The small intestine as a xenobiotic-metabolizing organ. Drug Metab Dispos, 31:1520-1525, 2003.

[44] Martignoni, M., Groothuis, G., de Kanter, R., Comparison of mouse and rat cytochrome P450mediated metabolism in liver and intestine. Drug Metab Dispos, 34:1047-1054, 2006. 